\title{
Strategi Komunikasi Pemasaran Majalah Tren Bogor dalam Upaya Menarik Minat Pemasang Iklan
}

\section{Marketing Communication Strategy Tren Bogor Magazine in Effort Interest of Advertiser}

\author{
N Purnamasari'1, U Suryatna², AA Kusumadinata ${ }^{3 a}$ \\ 1)Alumni Ps. Ilmu Komunikasi, Fakultas Ilmu Sosial dan Ilmu Politik, Universitas Djuanda Bogor. ${ }^{2)}$ Dosen \\ Pembimbing I Program Studi Komunikasi, Fakultas Ilmu Sosial dan Ilmu Politik, ${ }^{3)}$ Dosen Pembimbing II \\ Program Studi Komunikasi Universitas Djuanda Bogor, Jl. Tol No. 1 Kotak Pos 35 Bogor 16720 \\ a Korespondensi: AA Kusumadinata, Email: alialamsyahkusumadinata@gmail.com
}

(Ditelaah: 30-07-2016; Disetujui: 30-08-2016)

\begin{abstract}
Advertising is the "lifeblood" that sustains the survival of a media business. Entrepreneurs in the field of media business should be able to develop strategies and innovative ways to get advertisers as much as possible. Bogor Trend magazine as one of the relatively new magazine to survive must be able to compete with its competitors. This study aimed (1) to determine the activities of preparation of advertising marketing communication strategy, (2) to assess the implementation of the advertising marketing communication strategy, (3) to determine the effectiveness of advertising marketing communications strategy. This research was conducted at Bogor Trends Magazine and designed as a qualitative descriptive study. Informants research determined by purposive sampling technique. Data were collected through interviews, observation, and documentation later in qualitative analysis. The results showed that (1) the marketing communication strategy is based on the results of SWOT analysis and define market segmentation, targets and positioning (STP), (2) implementation of marketing communication strategy done through trend point, various forms of media, proactive strategies and promo package. (3) Trends Magazine marketing communications strategy Bogor has not had a positive impact, indicated by a decrease in the number of advertisers and revenue turnover. This decrease is caused by the region segmentation is too broad while the limited resources and the lack of consideration of potential and existing opportunities.

Keywords: Strategy, Marketing Communications, Advertising
\end{abstract}

\begin{abstract}
ABSTRAK
Iklan merupakan "urat nadi" yang menopang keberlangsungan hidup suatu bisnis media. Pengusaha di bidang bisnis media harus mampu mengembangkan strategi dan inovatif untuk mendapatkan pemasang iklan sebanyak-banyaknya. Majalah Tren Bogor sebagai salah satu majalah yang relatif baru untuk dapat bertahan hidup harus mampu bersaing dengan kompetitornya. Penelitian ini bertujuan (1) untuk mengetahui kegiatan penyusunan strategi komunikasi pemasaran iklan, (2) untuk mengetahui pelaksanaan strategi komunikasi pemasaran iklan, (3) untuk mengetahui efektivitas strategi komunikasi pemasaran iklan. Penelitian ini dilakukan pada Majalah Tren Bogor dan didesain sebagai penelitian deskriptif kualitatif. Informan penelitian ditentukan dengan teknik purposive sampling. Data dikumpulkan melalui wawancara, observasi, dan dokumentasi kemudian di analisis secara kualitatif. Hasil penelitian menunjukan bahwa (1) strategi komunikasi pemasaran disusun berdasarkan hasil analisis SWOT dan menetapkan segmentasi pasar, target dan positioning (STP), (2) implementasi strategi komunikasi pemasaran dilakukan melalui tren point, berbagai bentuk media, strategi jemput bola dan paket promo. (3) strategi komunikasi pemasaran Majalah Tren Bogor belum berdampak positif, diindikasikan dengan penurunan jumlah pemasang iklan dan pemasukan omzet. Penurunan ini disebabkan oleh segmentasi wilayah yang terlampau luas sedangkan sumber daya terbatas serta kurang mempertimbangkan potensi dan peluang yang ada.
\end{abstract}

Kata Kunci : Strategi, Komunikasi Pemasaran, Iklan

N Purnamasari, U Suryatna, AA Kusumadinata. 2016. Strategi Komunikasi Pemasaran Majalah Tren Bogor dalam Upaya Menarik Minat Pemasang Iklan. Jurnal Komunikatio 2(1): 115-124 


\section{PENDAHULUAN}

Perkembangan bisnis media cetak di Indonesia bertumbuh dengan pesat. Saat ini ada ratusan bahkan ribuan media cetak baru yang terbit dalam berbagai bentuk, seperti surat kabar, tabloid, buletin majalah dan sebagainya, baik yang berskala nasional, regional maupun lokal. Perkembangan tersebut dipicu setelah dihapuskannya Surat Izin Usaha Penerbitan (SIUP) setelah jatuhnya rezim Soeharto Dengan dicabutnya SIUP membuat usaha bisnis penerbitan media massa cetak mendapatkan kebebasan. Dalam bisnis media cetak sendiri iklan merupakan "urat nadi" yang menopang keberlangsungan hidup suatu media. Selain mengandalkan jumlah oplah yang dicetak dan dijual, bisnis media cetak juga ditopang oleh penghasilan dari iklan. Bahkan seringkali besarnya pendapatan dari iklan melampaui laba penjualan. Oleh karena itu mereka yang berkecimpung dalam bisnis media cetak harus mampu mengembangkan strategi dan menyusun langkah-langkah inovatif agar dapat bertahan hidup dalam persaingan bisnis media cetak yang semakin ketat dewasa ini yakni dengan upaya mendapatkan pemasangan iklan sebanyakbanyaknya.

Majalah memiliki karakteristik tersendiri yang membedakannya dengan surat kabar, yakni penyajiannya lebih dalam, nilai aktualits yang lebih lama, gambar atau foto yang lebih banyak, dan cover sebagai daya tarik. Majalah memiliki memiliki sasaran khalayak yang lebih spesifik. (Elvinaro, 2007). Jangkauan majalah hanya pada kelompok yang dituju, memiliki intensitas cukup tinggi, kelompok yang dituju tepat karena telah terpilih, dan memiliki biaya yang lebih murah (Soemanegara, 2006). Oleh karena itu dalam persaingan bisnis majalah yang ketat pengusaha harus mampu menerapkan strategi komunikasi pemasaran yang efektif agar mampu bersaing dengan kompetitornya.

Komunikasi pemasaran merupakan kegiatan komunikasi yang bertujuan untuk menyampaikan pesan pada konsumen dengan menggunakan berbagai media dengan harapan agar komunikasi dapat menghasilkan perubahan pengetahuan, sikap, dan tindakan yang dikehendaki (John E. Kennedy \& Dermawan, 2006). Komunikasi pemasaran adalah kegiatan pemasaran dengan menggunakan teknikteknik komunikasi yang ditujukan untuk memberikan informasi kepada orang banyak dengan harapan agar tujuan perusahaan dapat tercapai, yaitu terjadinya peningkatan pendapatan (laba) sebagai hasil penambahan penggunaan jasa atau pembelian produk yang ditawarkan tujuan komunikasi pemasaran ialah tahap perubahan knowledge, tahap perubahan sikap, dan tahap perubahan perilaku (Soemanegara, 2006).

Periklanan ialah merupakan pesanpesan penjualan yang paling persuasif yang diarahkan kepada para calon pembeli yang potensial atas produk barang atau jasa tertentu dengan biaya yang semurahmurahnya (Institut Praktisi Periklanan Inggris dalam Jefkins, 1997). Periklanan adalah semua bentuk penyajian dan promosi non personal atas ide, barang atau jasa yang dilakukan oleh perusahaan tertentu (Hermawan, 2012). Agar proses komunikasi pemasaran dapat berjalan sesuai dengan yang diharapkan oleh perusahaan diperlukan alat bantu atau strategi tertentu dalam pemasaran, diantaranya analisis SWOT, strategi pendekatan STP, promosi dan elemen lain dalam komunikasi pemasaran. Konsep dasar pendekatan SWOT ini digunakan untuk mengetahui kekuatan dan kelemahan perusahaan dan juga untuk mengetahui kekuatan dan kelemahan lawan untuk dapat menang dalam persaingan bisnis (Sun Tzu dalam Rangkuti, 1997). Sedangkan strategi STP untuk mengetahui segmentasi pasar, target pasar, dan positioning perusahaan. Oleh karena itu untuk mengetahui strategi komunikasi pemasaran yang dilakukan oleh Majalah Tren Bogor dalam upaya menarik minat pemasang iklan.

Penelitian ini bertujuan untuk (1) untuk mengetahui kegiatan penyusunan strategi komunikasi pemasaran yang dilakukan oleh Majalah Tren Bogor dalam upaya menarik minat pemasang iklan, (2) untuk mengetahui pelaksanaan strategi komunikasi pemasaran yang dilakukan oleh Majalah Tren Bogor dalam upaya menarik 
minat pemasang iklan, (3) untuk mengetahui efektivitas strategi komunikasi pemasaran yang dilakukan oleh Majalah Tren Bogor dalam upaya menarik minat pemasang iklan.

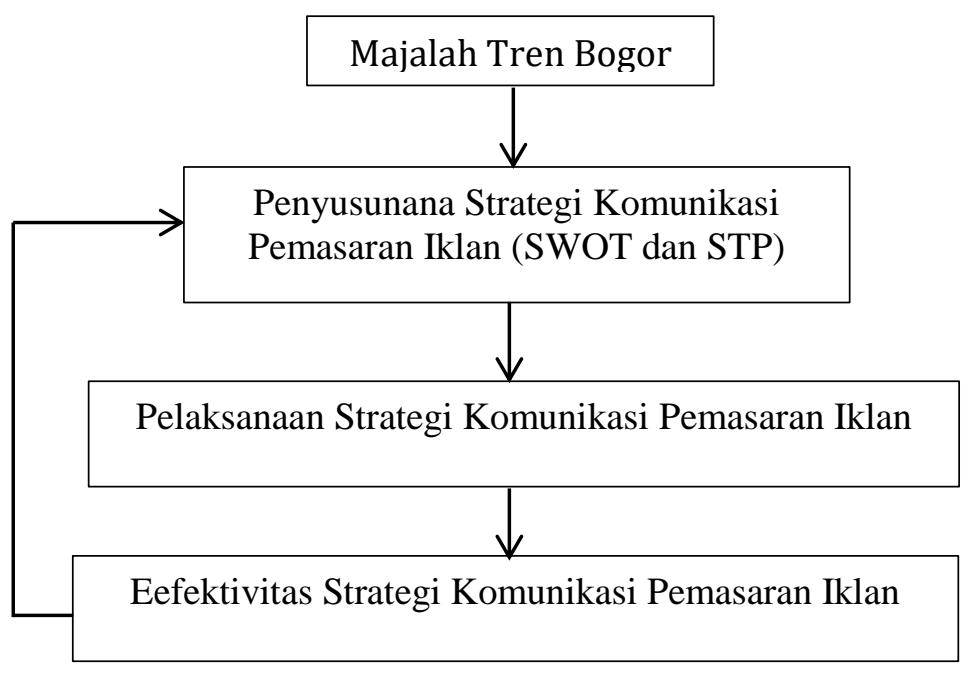

\section{Gambar 1 Strategi Komunikasi Pemasaran Majalah Tren Bogor dalam Upaya Menarik Minat Pemasang Iklan}

\section{MATERI DAN METODE}

Penelitian ini dilaksanakan di Kantor Majalah Tren Bogor menggunakan metode deskriptif dengan pendekatan kualitatif. Penelitian ini tidak bermaksud untuk menguji hipotetsis, tetapi hanya akan mendeskripsikan strategi komunikasi pemasaran yang diterapkan oleh Majalah Tren Bogor dalam upaya menarik minat pemasang iklan.

Unit analisis dalam penelitian ini adalah divisi marketing yang memiliki tugas dan fungsi pemasaran untuk pemasangan iklan di majalah tersebut. Informan penelitian ditentukan dengan menggunakan teknik purposive sampling, yang dianggap paling mengetahui mengenai penyusunan dan penerapan strategi komunikasi pemasaran ruang iklan Majalah Tren Bogor.

Data penelitian dikumpulkan melalui observasi, wawancara mendalam dan dokumen terkait, kemudian dianalisis secara kualitatif dengan cara reduksi data (data reduction), pengumpulan data (data collection), penyajian data (data display), dan penarikan kesimpulan (conclusion drawing/verification). 


\section{HASIL DAN PEMBAHASAN}

\section{Gambaran Umum Perusahaan}

Majalah Tren Bogor merupakan perusahaan media yang bergerak di bidang majalah. Perusahaan ini di bawah naungan PT. Wahana Semesta Merdeka (WSM) yang mengendalikan beberapa media seperti koran-koran dan televise lokal yang berada di bawah bendera Grup Jawa Pos untuk wilayah Jawa dan Sumatera. Majalah Tren Bogor ini merupakan majalah yang penyebarannya di wilayah Kota dan Kabupaten Bogor. Majalah ini mengupas seputar gaya hidup dan komunitas. Majalah Tren Bogor ini pertama Go Publish pada Oktober 2011.
Majalah Tren Bogor memiliki tagline "Majalah Komunitas dan Gaya Hidup", majalah ini membahas tentang gaya hidup dan komunitas yang ada di wilayah Kota dan Kabupaten Bogor yang diulas secara lebih eksklusif dan mendalam. Segmen pembaca majalah ini ialah pembaca kelas menengah ke atas dengan kisaran pembaca wanita sebanyak $60 \%$ wanita dan $40 \%$ pria (sumber:dokumen Majalah Tren Bogor). Strategi komunikasi pemasaran Majalah Tren Bogor disusun berdasarkan analisis SWOT kemudian menetapkan segmentasi pasar, target pasar, dan positioning (STP), kemudian implementasi strategi meliputi strategi promosi, pemasaran langsung, penjualan personal, dan promosi penjualan.

Tabel 1 SWOT (Strenght, Weakness, Opportunity, dan Threat

\begin{tabular}{lll}
\hline & Bermanfaat & Berbahaya \\
\hline Faktor Internal & Kekuatan (Strenght) & Kelemahan (Weakness) \\
& - Segmen Pembaca Jelas & - Penyebaran kurang \\
& - Eksklusif & merata \\
& - Kualitas Bagus & - Oplah terbatas \\
& - Jaringan distribusi & - Kurang Promosi \\
Fakor Ekternal & - Harga iklan terbaik & - Kurang SDM \\
& Peluang (Opportunity) & Ancaman (Threat) \\
& - Pangsa Pasar Positif & - Kenaikan BBM dengan \\
& - Sudah dikenal di wilayah & - Persaingan dan dengan beriklan yang \\
\hline
\end{tabular}

Berdasarkan Tabel 1, Kekuatan dan peluang yang dimiliki oleh Majalah Tren Bogor bisa dimanfaatkan untuk meminimalisir kelemahan dan dampak dari ancaman yang bisa merugikan perusahaan. Penggunaan analisis SWOT ini dapat dipergunakan oleh perusahaan sebagai dasar dalam menyusun langkah-langkah strategis dalam upaya menarik minat pemasang iklan. Maka dari itu diperlukan pertimbangan-pertimbangan yang matang dalam menggunakan secara maksimal kekuatan dan peluang yang ada pada perusahaan. Setelah melakukan analisis
SWOT, langkah selanjutnya yang dilakukan oleh Majalah Tren Bogor ialah menerapkan strategi STP. Strategi ini dipergunakan untuk mengetahui segmen-segmen pasar, target pasar, dan positioning yang ingin dibentuk dalam benak masyarakat oleh perusahaan itu sendiri. Strategi STP ini bisa dilihat dalam Tabel 2 yang ada di bawah ini. 
Tabel 2 Segmenting, Targeting, dan Positioning

\begin{tabular}{|c|c|}
\hline \multicolumn{2}{|r|}{ SEGMENTING } \\
\hline Segmentasi Geografis & Wilayah Kota dan Kabupaten Bogor \\
\hline Segmentasi Demografis & $\begin{array}{l}\text { Dilihat berdasarkan usia, diincar pemasang iklan yang berusia 20- } \\
70 \text { tahun }\end{array}$ \\
\hline Segmentasi Psikografis & $\begin{array}{l}\text { masyarakat dengan gaya hidup kelas menengah ke atas, karena } \\
\text { dinilai merupakan klien yang potensial dan dinilai cocok jika } \\
\text { memasang iklan di Majalah Tren Bogor }\end{array}$ \\
\hline Segmentasi Perilaku & $\begin{array}{l}\text { kelompok-kelompok pelaku usaha, organisasi, lembaga, institusi, } \\
\text { eksekutif muda, mahasiswa/i yang berwirausaha. Orang-orang } \\
\text { yang dinilai memiliki pengetahuan yang cukup akan jasa yang } \\
\text { ditawarkan }\end{array}$ \\
\hline
\end{tabular}

Berdasarkan tabel 2, strategi STP ini dilakukan untuk mengetahui segmen dan target pemasang iklan yang seperti apa yang diinginkan oleh Majalah Tren Bogor. Dari segmentasi wilayah, terlihat Majalah Tren Bogor memiliki cakupan segmen di wilayah Kota dan Kabupaten Bogor, segmentasi demografisnya berdasarkan usia 20-70 tahun, kemudian dari segmentasi psikografis yakni masyarakat Bogor kelas menengah ke atas, dan segmentasi perilaku merupakan orangorang yang dianggap memiliki pengetahuan yang cukup mengenai produk. Sedangkan berdasarkan target pemasang iklan yang dituju oleh Majalah Tren Bogor ialah dari kalangan menengah ke atas, karena dinilai tepat jika memasang iklan di Majalah Tren Bogor yang memiliki segmen pembaca kelas menengah ke atas. Selain itu juga dilihat dari kondisi keadaan dari calon pemasang iklan itu sendiri karena harga iklannya mulai dari Rp 4 juta hingga Rp 10 juta. Untuk analisis positioning, majalah Tren Bogor ditujukan untuk masyarakat Bogor kelas menengah ke atas dan pengunjung yang sedang berwisata ke Bogor. Karena Majalah Tren Bogor berisikan informasi tentang tempat-tempat wisata, penginapan, dan gaya hidup yang sedang tren. Berdasarkan hasil penelitian, diketahui untuk menarik minat pemasang iklan yang dituju ditentukan berdasarkan:

\section{Penentuan posisi menurut manfaat}

Produk diposisikan sebagai pemimpin dalam suatu manfaat tertentu. Dalam kasus Majalah Tren Bogor, manfaat yang ditonjolkan ialah sebagai majalah referensi atau map bagi masyarakat atau pengunjung yang datang ke Bogor.

\section{Penentuan posisi harga atau kualitas}

Produk diposisikan sebagai penawar nilai terbaik. Majalah Tren Bogor menawarkan nilai terbaik untuk harga yang sebanding dengan informasi yang didapatkan. Produk ini dipasarkan kepada kelompok kelas menengah ke atas.

Analisis STP digunakan untuk mengetahui siapa yang akan dijadikan target pemasang iklan setelah dilakukan pengelompokan pasar (segmentasi) . Metode STP digunakan untuk mengetahui target potensial sesuai dengan tujuan yang diinginkan oleh perusahaan, sehingga nantinya akan dirancang strategi komunikasi pemasaran yang efektif untuk menarik minat pemasang iklan sebanyak-banyaknya. Kedudukan suatu Majalah Tren Bogor yang menempatkan diri sebagai majalah referensi bagi masyarakat dan pengunjung yang datang ke Bogor akan berpengaruh dalam pelaksanaan strategi komunikasi pemasaran yang dilakukan oleh Majalah Tren Bogor.

\section{Strategi Promosi}

Melalui strategi promosi, diharapkan brand awareness konsumen dapat meningkat. 
Adapun strategi mempromosikan diri yang dilakukan oleh Majalah Ten Bogor antara lain:

1. Distribusi ke sejumlah tren point

Majalah Tren Bogor mengandalkan promosi dengan cara menyebarluaskan diri ke sejumlah tempat-tempat yang sesuai dengan segmen pembacanya dengan harapan dapat menarik perhatian segmen pembaca dan menarik minat pemasang iklan yang telah ditetapkan sebelumnya. Tempat-tempat penyebaran Majalah Tren Bogor biasa disebut dengan Tren Point. Tren Point ialah tempat tempat dimana segmen pembaca dan target pemasang iklan berkumpul di suatu tempat.

\section{Poster dan spanduk}

Spanduk dan poster yang disebarkan di mall-mall dan sejumlah tempat keramaian yang berada di sekitar area Kabupaten dan Kota Bogor.

\section{Radio}

Promosi lainnya yang dilakukan Tren Bogor ialah bekerjasama dengan sejumlah radio yang ada di Bogor untuk lebih dikenal oleh masyarakat Bogor. Melalui pesan yang disampaikan melalui radio, Majalah Tren Bogor bermaksud untuk menyampaikan kepada khalayak yang ada di Bogor mengenai Majalah Tren Bogor. Seperti publikasi yang dilakukan di Radio Lesmana FM.

\section{Menjadi media partner}

Selain mengandalkan sejumlah promosi yang dilakukan melalui poster, penyebaran majalah, dan radio, Majalah Tren Bogor juga melakukan promosi dirinya dengan berusaha menjadi media partner sejumlah acara baik yang diselenggarakan oleh pelajar, mahasiswa, swasta, hingga ke pemerintahan. Tujuannya tidak lain sebagai penunjukkan eksistensi diri baik untuk pesaing maupun untuk masyarakat.

\section{Pemasaran Langsung}

Pemasaran secara langsung yang dilakukan oleh divisi marketing Majalah Tren Bogor adalah

a) strategi jemput bola

Strategi ini dilakukan mengingat keberadaan Majalah Tren Bogor yang belum dikenal oleh seluruh lapisan masyarakat yang ada di Bogor, khususnya kabupaten Bogor.. strategi jemput bola yakni dengan mendatangi sejumlah calon pemasnag iklan potensial yang akan diajak negosiasi mengenai pemasangan iklan di Majalah Tren Bogor. Strategi jemput bola ini juga berpengaruh dalam pelaksanaan promosi, dengan mendatangi langsung target yang ingin dicapai.

b) melalui telpon, sms, dan e-mail.

Pemasaran langsung lainnya yakni dengan memanfaatkan berbagai media komunikasi yang ada seperti telepon, sms, dan e-mail. Penggunaan internet dalam pemasaran langsung sangat berguna demi memanjakan konsumen dan mempermudah proses pemasaran Pemasaran langsung digunakan memudahkan perusahaan untuk berinteraksi dan mengetahui keinginan calon konsumen, serta membuat database konsumen yang ingin dijadikan sasaran (Hermawan, 2012).

\section{Penjualan Personal}

Hal yang dilakukan selama penjualan personal dalam rangka upaya menarik minat pemasang iklan ialah:

a) melakukan pendekatan dengan membujuk

b) negosiasi harga

Setelah melakukan pendekatan personal, kemudian yang dilakukan selanjutnya ialah membicarakan harga. Untuk setiap iklan yang ada di Majalah Tren Bogor memiliki harga yang bervariasi tergantung ukuran iklannya. Namun harga tersebut bukan merupakan fixed price atau harga tetap. Masalah harga iklan masih bisa disesuaikan dengan budget yang dimiliki oleh klien. Hal ini untuk menarik perhatian calon 
pemasang iklan dengan dana yang terbatas. Jika sudah mengetahui budget yang dimiliki klien, hal selanjutnya yang dilakukan divisi marketing ialah menawarkan space iklan yang sesuai dengan budget klien.

c) barter iklan

Barter ini merupakan penawaran iklan dalam bentuk saling tukar-menukar barang atau jasa yang telah disepakati kedua belah pihak. Barter ini biasanya berupa barter berbentuk iklan dengan perusahaan klien, yang dimana hasilnya nanti Majalah Tren Bogor pun bisa memasang iklan di perusahaan klien. Barter iklan ini memiliki batas waktu tersendiri tergantung dari kerja sama yang telah disepakati oleh kedua belah pihak.

\section{Promosi Penjualan}

Bentuk-bentuk strategi komunikasi pemasaran yang dilakukan dalam bentuk promosi penjualan yaitu:

a) Paket Iklan 3 Bulan

b) Paket iklan 6 bulan

c) paket iklan 12 bulan

d) Cicilan Pembayaran

Sistem cicilan ini dimaksudkan untuk memudahkan pembayaran iklan dalam jangka waktu tertentu jika pemasang iklan belum memiliki dana yang cukup untuk satu kali bayar. Sistem cicilan pembayaran ini bisa disesuaikan dengan jangka waktu sesuai dengan pembelian yang dilakukan oleh pemasang iklan. Misalnya, jika klien memasang iklan selama 5 bulan, maka pembayaran bisa dilakukan dalam jangka waktu tersebut.

e) Memberi pelayanan ekstra berupa peliputan dan materi iklan dijemput secara langsung.

Tabel 3 Dampak Strategi Komunikasi Pemasaran Terhadap Pertambahan Pengiklan

\begin{tabular}{|c|c|c|c|c|}
\hline \multirow{2}{*}{ Kategori } & \multicolumn{3}{|c|}{ Bulan } & \multirow[b]{2}{*}{ Total Kategori } \\
\hline & Februari & Maret & April & \\
\hline Perbankan & 1 & 1 & 1 & 3 \\
\hline Perhotelan & 2 & 4 & 2 & 8 \\
\hline Institusi Pendidikan & 3 & 2 & 1 & 6 \\
\hline Café \& Resto & 3 & 2 & 1 & 6 \\
\hline Properti & 3 & 2 & 1 & 6 \\
\hline Sorum & 5 & 3 & 3 & 11 \\
\hline Rumah Sakit & 1 & 1 & & 2 \\
\hline Mall & & 1 & 1 & 2 \\
\hline Tempat Wisata & 3 & 1 & 2 & 6 \\
\hline Manajemen Musik & 2 & 5 & 4 & 11 \\
\hline $\begin{array}{l}\text { Lain-Lain (toko furniture, } \\
\text { penjual jasa, toko jaket, optic, } \\
\text { produk makanan, salon, toko } \\
\text { pakaian) }\end{array}$ & 23 & 20 & 22 & 65 \\
\hline Total Jumlah & 45 & 41 & 38 & 126 \\
\hline
\end{tabular}




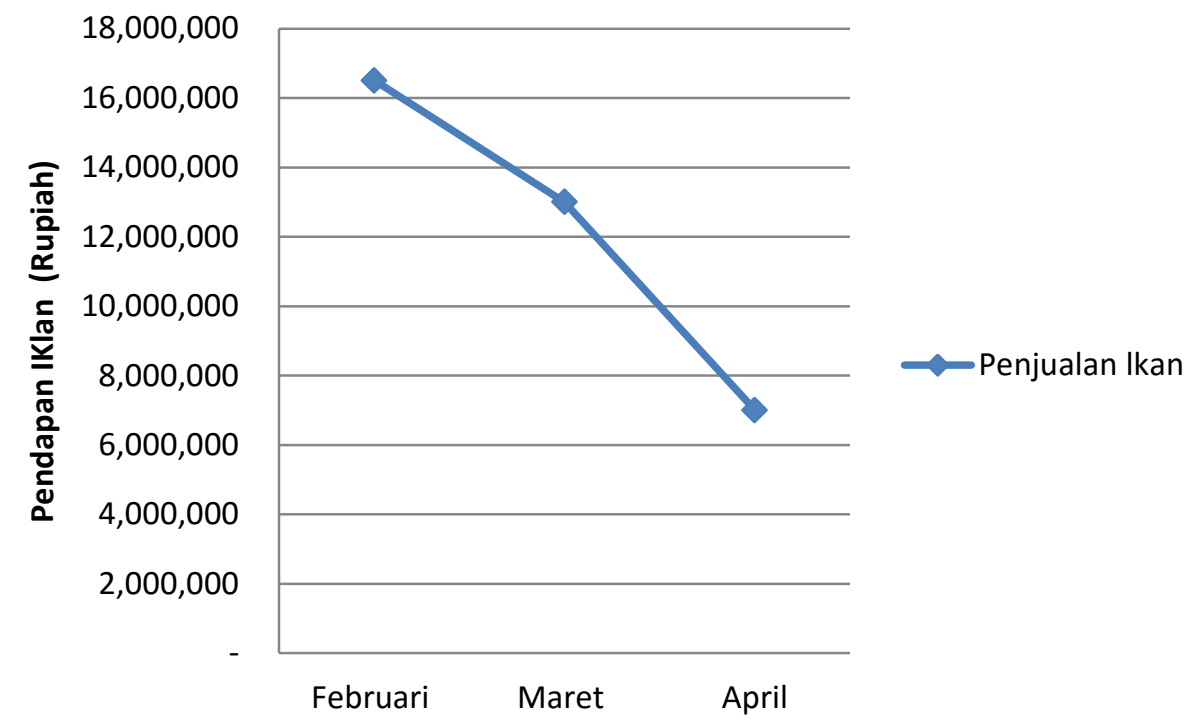

Gambar 2 Omset Pendspatan Iklan 2015

Dari grafik garis yang disajikan di Gambar 2, pendapatan Majalah Tren Bogor dari Rp 16 juta turun hingga angka Rp 7 juta di bulan akhir penelitian. Berdasarkan data pemasang iklan dan jumlah perolehan pendapatan yang di dapat selama tiga bulan, strategi komunikasi pemasaran yang telah dilakukan oleh Majalah Tren Bogor belum berdampak positif terhadap peningkatan pemasang iklan di Majalah Tren Bogor.

Berdasarkan hasil analisis, penentuan segmentasi pasar yang luas yang berada di wilayah Kota dan Kabupaten Bogor, bisa jadi merupakan salah satu faktor belum berdampaknya strategi komunikasi pemasaran yang diterapkan oleh Majalah Tren Bogor. Segmentasi pasar yang luas tidak didukung oleh sumber daya manusia yang mencukupi, sehingga target yang potensial belum bisa terjangkau oleh tim pemasaran Majalah Tren Bogor.

Berdasarkan hasil analisis dan wawancara, faktor ancaman kenaikan BBM juga berpengaruh besar terhadap minat target untuk memasang iklan di majalah, meskipun Majalah Tren Bogor memiliki kekuatan di harga iklan yang bisa dinegosiasi, namun sejak adanya kenaikan BBM ini banyak perusahaan yang mengurangi dana promosi di majalah 


\section{KESIMPULAN DAN IMPLIKASI}

\section{Kesimpulan}

1. Kegiatan penyusunan strategi yang dilakukan oleh divisi marketing Majalah Tren Bogor penentuan faktor internal (kekuatan dan kelemahan) dan faktor eksternal (peluang dan ancaman) yang dimiliki perusahaan melalui analisis SWOT. Kemudian menetapkan segmen pasar, target pasar, dan positioning melalui analisis STP yang nantinya berpengaruh pada pengimplementasian strategi promosi, pemasaran langsung, personal selling, dan promosi penjualan.

2. Pengimplementasian strategi komunikasi pemasaran ruang iklan Majalah Tren Bogor dimulai dari strategi promosi yang tujuannya untuk meningkatkan kesadaran konsumen akan produk. Strategi promosi terdiri dari: distribusi ke sejumlah tren point, poster dan spanduk, radio, dan media partner. Kemudian langkah strategi selanjutnya ialah melalui pemasaran langsung yang meliputi strategi jemput bola dan melalui telpon, sms, atau e-mail. Personal selling pun menjadi salah satu strategi yang diterapkan oleh Majalah Tren Bogor kegiatannya antara lain melakukan pendekatan melalui komunikasi persuasif, negosiasi harga, dan barter iklan. Langkah terakhir dalam strategi komunikasi pemasaran yang dilakukan oleh Majalah Tren Bogor adalah melakukan promosi penjualan dimana dalam masa promo, target yang dituju akan mendapatkan harga paket iklan yang lebih murah dan pelayanan khusus. Paket promo tersebut antara lain paket iklan 3 bulan, paket iklan 6 bulan, dan paket 12 bulan. Untuk fasilitasnya, pembayaran bisa dilakukan dengan sistem cicilan, dan kemudian pelayanan khusus lainnya yakni materi iklan dijemput langsung dan tawaran peliputan khusus.

3. Dilihat dari perolehan data selama tiga bulan, angka jumlah pemsang iklan dan pemasukan omzet yang diperoleh Majalah Tren Bogor mengalami penurunan angka. Hal ini menunjukkan bahwa strategi komunikasi pemasaran yang dilakukan oleh Majalah Tren Bogor belum berdampak positif terhadap perusahaan. Penurunan ini dapat disebabkan karena segmentasi wilayah yang terlampau luas namun sedangkan sumber daya yang dimilikinya terbatas. Ancaman kenaikan BBM juga berpengaruh terhadap menurunnya jumlah pemasang iklan di Majalah Tren Bogor. Berdasarkan hasil wawancara, banyak perusahaan yang mengalihkan dana promosi mereka setelah kenaikan BBM.

\section{Implikasi}

1. Pemanfaatan analisis SWOT yang dimiliki perusahaan sebaiknya terus dioptimalkan. Mencari suatu cara dalam pemanfaatan kekuatan dan peluang untuk mengatasi ancaman dan kelemahan agar bisa menyusun strategi komunikasi pemasaran sesuai dengan target pasar yang diinginkan. Kelemahan yang dimiliki seperti kurannya sumber daya manusia dalam pemasaran ruang iklan sebaiknya bisa diatasi dengan penambahan SDM jika ingin menjangkau segmen pasar yang luas baik di wilayah Kota maupun Kabupaten Bogor.

2. Perlunya menambah dan mengevaluasi strategi yang sudah dilaksanakan, karena segmen pasar yang ingin dicapai pun luas. Penambahan jumlah strategi komunikasi pemasaran harus dibarengi dengan penambahan sumber daya manusia. Penambahan strategi komunikasi pemasaran dapat berupa pemasaran langsung yang memanfaatkan perkembangan teknologi internetmengadakan event tertentu di wilayah-wilayah tempat berkumpulnya target sasaran, atau mengadakan kegiatan amal di bulan-bulan tertentu. 


\section{DAFTAR PUSTAKA}

Assauri S. 2002. Manajemen Pemasran Dasar Konsep \& Strategi, PT.Raja Grafindo Persada, Jakarta.

Ardianto, dkk. 2007. Komunikasi Massa. Suatu Pengantar. Edisi Revisi. Simbiosa Rekatama Media. Bandung.

Jefkins, Frank. 1997. Periklanan. Erlangga. Jakarta.

Hermawan, Agus. 2012. Komunikasi Pemasaran. Erlangga. Jakarta.

Kennedy, John. E; R Dermawan Soemanagara., 2006. Marketing Communication - Taktik dan Strategi. Jakarta. PT Buana Ilmu Populer (kelompok Gramedia).

Morissan, M.A. 2010). Teori Komunikasi Massa. Ghalia Indonesia. Jakarta.

Morissan, (2013). Teori Komunikasi: Individu Hingga Massa. Kencana Prenada Media Group. Jakarta.

Rangkuti, Freddy. (2014). Analisis SWOT: Cara Perhitungan Bobot, Rating, dan OCAI. Jakarta: Gramedia Pustaka Utama.

Romli ASM. 2012. Jurnalistik Online. Bandung: Nuansa Cendekia.

Shimp AT. 2000. Promosi dan Periklanan. Aspek Tambahan Komunikasi Pemasaran Terpadu. Jakarta: Erlangga.

Soemanegara. 2006. Strategic Marketing Communication: Konsep Strategis dan Terapan. Bandung: Alfabeta.

Sugiyono. 2011. Metode Penelitian Kuantitatif, Kualititatif, dan R\&D. Bandung : Alfabeta.
Chorunnisak. 2012. Penerapan Analisis SWOT Dalam Strategi Pemasaran Produk Tabungan Pada BMI Cabang Pembantu Magelang. Salatiga. Sekolah Tinggi Agama Islam Negeri (STAIN).

Imaroh, Laily. 2013. Analisis STP dan 4P dalam Produk Ultra Milk. Syariah Ekonomi Islam. STAIN Kudus.

Gunawan Adi Chandra dan Serli Wijaya. 2010 . Analisa Segmentasi, Penentuan Target, dan Posisi Pasar pada Restoran Steak dan Grill di Surabaya.

Aditya. 2012. Catatan Kecil Manajemen Pemasaran. Positioning Produk Barang dan Jasa (http://aditya39e.blogstudent.mb.ipb .ac.id/2012/02/23/positioningpemasaran/). Diakses pada 12 April 2015.

Ebiz Consultant. 2013. Analysis SWOT dan STP.

(https://ebizconsultants.wordpress.c om/2013/02/05/analisis-swot-andstp/). Diakses pada 13 Maret 2015.

Denny Bagus. (2009). Segmentasi Pasar : Definisi Manfaat dan Kelemahan (http://jurnalsdm.blogspot.com/2009/07/segment asi-pasar-definisi-manfaat-dan.html). Diakses pada 5 April 2015.

Muhammad Fajar, dkk. (2011). Contoh Kasus Penerapan STP (http://stpgroup.blogspot.com/p/con toh-kasus.html). Diakses pada 1 April 2015

Rahdinal. (2011). Definisi Majalah (http://rahdinalspaceart.blogspot.co $\mathrm{m} / 2011 / 11 /$ definisi-majalahmajalahadalah-sebuah.html). Diakses pada 24 Februari 2015. 